\title{
Analysis of Maximum Wind force for Offshore Structure Design
}

Jing-Jong Jang

Associate Professor, Department of Harbor and River Engineering, National Taiwan Ocean University, 2 Pei-Ning Road, Keelung 20224, Taiwan

Guo Jyh-Shinn

Graduate student, Department of Harbor and River Engineering, National Taiwan Ocean University.

Follow this and additional works at: https://jmstt.ntou.edu.tw/journal

Part of the Civil and Environmental Engineering Commons

\section{Recommended Citation}

Jang, Jing-Jong and Jyh-Shinn, Guo (2009) "Analysis of Maximum Wind force for Offshore Structure Design," Journal of Marine Science and Technology. Vol. 7: Iss. 1, Article 6.

DOI: $10.51400 / 2709-6998.2511$

Available at: https://jmstt.ntou.edu.tw/journal/vol7/iss1/6

This Research Article is brought to you for free and open access by Journal of Marine Science and Technology. It has been accepted for inclusion in Journal of Marine Science and Technology by an authorized editor of Journal of Marine Science and Technology. 


\section{Analysis of Maximum Wind force for Offshore Structure Design}

Acknowledgements

The authors would like to thank the National Science Council of Taiwan for funding this research (Project No. NSC 87-2611-019-030) 


\title{
ANALYSIS OF MAXIMUM WIND FORCE FOR OFFSHORE STRUCTURE DESIGN
}

\author{
Jing-Jong Jang* and Guo Jyh-Shinn**
}

Keywords: Wind Force, Offshore Structure, Structure Design, Probability Density Function.

\begin{abstract}
This paper presents the results of a study in which a method is developed for estimating maximum turbulent wind drag force acting on a floating offshore structure with low natural frequency. In evaluating the drag force, forces associated with turbulent wind speeds are considered using both the linear and nonlinear reliability analysis approaches. A mathematical wind spectral density formulation is employed. The probability density function applied for the maximum turbulent wind-induced drag force analysis is considered as a random process. The maximum wind force is analytically developed by using an approximate single term expression for the functional relationship between the wind speed and the associated turbulent drag force. At last, the probable maximum and the design maximum values are estimated by applying maximum value statistics and reliability analysis.
\end{abstract}

\section{INTRODUCTION}

Estimation of the magnitude of wind-induced loading (drag force) on offshore structures provides information vital for the design and operation of the structures; in particular for floating structures in a seaway. The wind-induced drag force referred to in the present study is that associated with turbulent winds consisting of various frequencies which span a very wide range. The frequency $\omega$ may vary from nearly zero to $1.5 \mathrm{rps}$ or higher.

Although many studies have been carried out evaluate turbulent wind-induced forces on offshore structures [Ref. 1 to 14 ], it is common practice to assume that the wind-induced drag force increases linearly with increase in wind fluctuating speed; neglecting the higher order term of the force which is proportional to the

Paper Received Feb. 10, 1999. Revised June 11, 1999. Accepted June 18, 1999. Author for Correspondence: Jing-Jong Jang.

*Associate Professor, Department of Harbor and River Engineering, National Taiwan Ocean University, 2 Pei-Ning Road, Keelung 20224, Taiwan.

**Graduate student, Department of Harbor and River Engineering, National Taiwan Ocean University. square of turbulent wind speed. The approximation appears to be acceptable for evaluating forces on buildings on land, but its use is highly questionable for evaluating the forces on marine structures. This is because some natural frequencies of motions of floating offshore structures are very small; on the order 0.01 to $0.02 \mathrm{~Hz}$ for the surging motion of a tension-leg platform, which is the domain where turbulent wind energy over a seaway is extremely high.

Thus, in evaluation turbulent wind-induced drag force on offshore structures in a seaway, significant questions arise as to the assurance with which predictions can be made when the estimations are obtained (i) by neglecting higher order drag force, and (ii) by using turbulent wind spectral formulations which are developed based on wind data measured primarily on land.

The results of a recent study on turbulent wind spectra have indicated that the measured wind spectral densities over a seaway are much larger at low frequencies than those computed by any of the currently available spectral formulation [9].

It may be well to elaborate on the low frequency turbulent winds. Figure 1 taken from Ref. [2] shows an example of a time history of wind speed. As demonstrated in the figure, the turbulent winds consist of several frequencies. In other words, the high frequency fluctuating winds are most discernible; however, the energy density of these high frequency components in the turbulent wind spectrum is relatively small over the seaway. Instead, the mean value of the time history as indicated by the dotted line in the figure and components with frequencies lower than those shown by the dotted line have extremely large energy densities. Since the response frequencies of offshore structures are low, extreme care must be taken in evaluating wind force on the structures when a substantial amount of wind energy exists at low frequencies.

This paper presents the results of a study in which a method is developed for estimating low frequency turbulent wind drag force (including maximum values) acting on a floating offshore structure. In evaluating the drag force, forces associated with turbulent wind speeds 


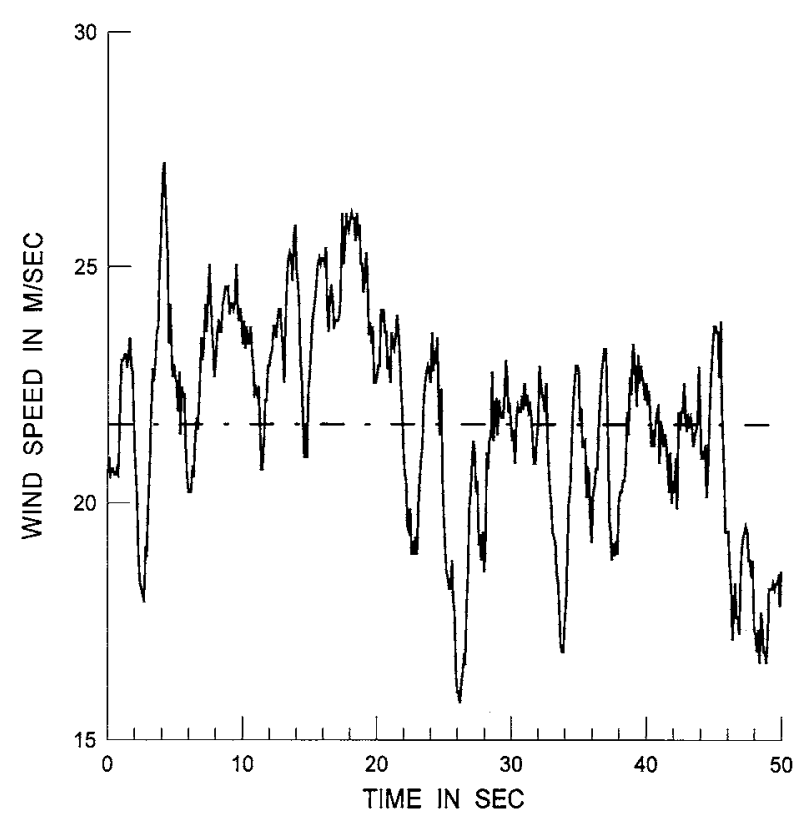

Fig. 1. Example of time history of wind speed.

are considered using both the linear and nonlinear (squared term) approaches. The probability density function applicable for the peaks of the turbulent windinduced drag force is analytically developed. Further, the probable extreme and the design extreme values are estimated by applying extreme value statistics.

\section{WIND-INDUCED DRAG FORCE ACTING ON OFFSHORE STRUCTURES}

\section{Turbulent Wind-Induced Drag Force}

The wind-induced drag force acting on offshore structures over a seaway can be evaluated, in general, by applying the following fundamental equation of drag force in aerodynamics:

$$
F_{D}(T)=\frac{1}{2} \rho C_{D} A U^{2}(t)
$$

where $\rho=$ air density

$C_{D}=$ drag coefficient

$A=$ projected area of a structure

$U(t)=$ incident wind speed.

The incident wind speed, $U(t)$, consists of two components; one a constant wind speed depending on the height above the sea level, denoted by $\bar{U}$; the other a randomly fluctuating turbulent wind speed, denoted by $w(t)$. That is,

$$
U(t)=\bar{U}+w(t)
$$

Thus, from Egs. (1) and (2), the wind-induced drag force, $F_{D}(t)$ can be written as follows:

$$
\begin{aligned}
F_{D}(t) & =\frac{1}{2} \rho C_{D} A\{\bar{U}+w(t)\}^{2} \\
& =\frac{1}{2} \rho C_{D} A \bar{U}^{2}+\rho C_{D} A \bar{U} w(t)+\frac{1}{2} \rho C_{D} A w(t)|w(t)|
\end{aligned}
$$

Here, the squared wind velocity is expressed as $w(t)|w(t)|$ so that the direction of drag force is in line with wind velocity.

The first term of Eq. (3) is called the mean drag force, denoted by $\bar{F}_{D}$, which is constant for a given mean wind speed. That is,

$$
\bar{F}_{D}=\frac{1}{2} \rho C_{D} A \bar{U}^{2}
$$

The second and third terms of Eq. (3) are the forces associated with turbulent winds, denoted by $\Delta F_{D}$. By applying the relationship given in Eq. (4), $\Delta F_{D}(t)$ can be expressed in terms of mean wind speed and associated drag force as follows:

$$
\begin{aligned}
\Delta F_{D}(t) & =\frac{2 \bar{F}_{D}}{\bar{U}} w(t)+\frac{\bar{F}_{D}}{\bar{U}^{2}} w(t)|w(t)| \\
& =a w(t)+b w(t)|w(t)|
\end{aligned}
$$

where $\mathrm{a}$ and $\mathrm{b}$ are constants for a given mean wind speed $\bar{U}$. These are,

$$
a=\frac{2 \bar{F}_{D}}{\bar{U}} \text { and } b=\frac{\bar{F}_{D}}{\bar{U}^{2}}
$$

In evaluating the wind-induced force on structures, the second term of Eq. (5) is generally neglected. However, as discussed in the Introduction, the linear as well as the nonlinear terms of turbulent winds in Eq. (5) are considered in the present study for evaluating the magnitude of forces acting on offshore structures.

It is assumed that the fluctuation of turbulent wind speed $w(t)$ is a Gaussian random process with zero mean. That is, for a given time $t$, the probability density function of $w$ is given by,

$$
f(w)=\frac{1}{\sqrt{2 \pi} \sigma} e^{-\frac{w^{2}}{2 \sigma^{2}}}-\infty<w<\infty
$$

where $\sigma^{2}=$ variance of turbulent winds

By applying the technique for changing random variables, it can be derived that the probability density function of $w|w|=z$ becomes the following $x^{2}$-distribution with one degree of freedom:

$$
f(z)=\frac{1}{2 \sigma \sqrt{2 \pi|z|}} e^{-\frac{|z|}{2 \sigma^{2}}} \quad-\infty<z<\infty
$$

Since the random variable $\Delta F_{D}$ is the sum of two dependent random variables, aw and bw $|w|$, the prob- 


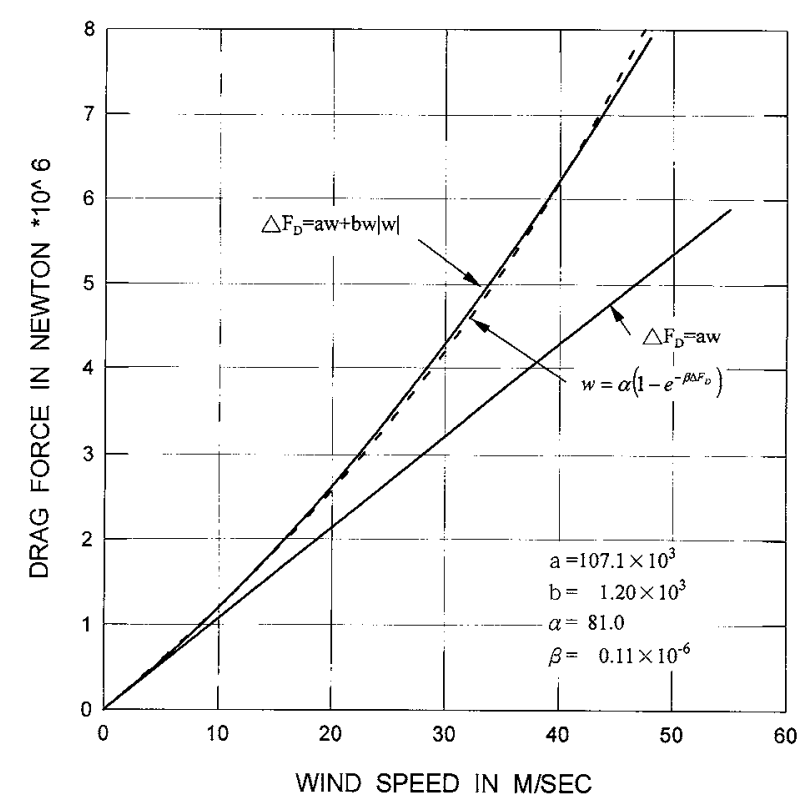

Fig. 2. Turbulent wind-induced drag force as a function of wind speed.

ability density function of $b w|w|$ is somewhat complicated to derive. Furthermore, the analytical derivation of the probability density function of the peaks of the random process $\Delta F_{D}$ cannot be achieved in closed form following Eq. (5).

One way to overcome this difficulty is to approximately express the functional relationship given in Eq. (5) by expressing wind speed by a single term having the following exponential form:

$$
w=\left\{\begin{array}{lll}
\alpha\left[1-\exp \left\{-\beta \Delta F_{D}\right\}\right] & \text { for } & \Delta F_{D} \geq 0 \\
-\alpha\left[1-\exp \left\{\beta \Delta F_{D}\right\}\right] & \text { for } & \Delta F_{D} \leq 0
\end{array}\right.
$$

Here, $\alpha$ and $\beta$ are constants to be determined such that the mean square difference between the drag forces, $\Delta F_{D}$, computed from Eqs. (5) and (9) is minimal.

As a numerical example, computations are carried out to evaluate the drag force at 30 meter height above the mean sea level on an offshore structure having a projected area $A=2 \times 10^{3} \mathrm{~m}^{2}$. The mean wind speed used in the computations is $44.7 \mathrm{~m} / \mathrm{sec}$ ( 87 knots) at $30 \mathrm{~m}$ height, which is $38.5 \mathrm{~m} / \mathrm{sec}$ (75 knots) at 10 meter height above the water surface. The drag coefficient, $C_{D}$, is taken as unity, while the air density, $\rho$, is taken as $1.20 \mathrm{~kg} / \mathrm{m}^{3}$. With these values, Eq. (6) yields $\alpha=$ $107.1 \times 10^{3}$ and $b=1.20 \times 10^{3}$, and there by $\alpha=81.0$ and $\beta=0.11 \times 10^{-6}$ are chosen so that Eq. (9) represents Eq. (5)with sufficient accuracy.

Figure 2 shows a comparison of drag forces $\Delta F_{D}$ computed for various turbulent wind speeds, $w$, by Eqs. (5) and (9). Included also in the figure is the first term

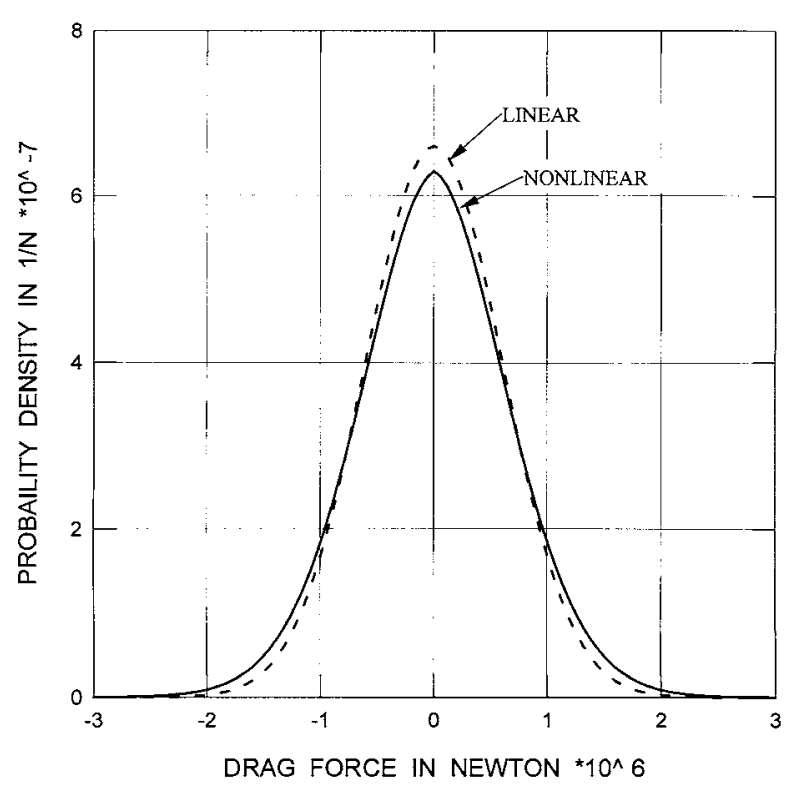

Fig. 3. Probability density functions of peak drag forces evaluated through linear and nonlinear approaches( $=44.7 \mathrm{~m} / \mathrm{sec}$., 87 knots $)$.

of Eq. (5) which is equivalent to the linear assumption, As can be seen in the figure, Eq. (9) represents well the drag force given by Eq. (5). The significance of the nonlinear term in evaluating the drag force induced by turbulent winds is also apparent.

By applying the functional relationship given in Eq. (9), to the probability density function of the wind speed given in Eq. (7), the probability density function of the turbulent drag force, including the nonlinear term can be derived as follows:

$$
\begin{aligned}
f\left(\Delta F_{D}\right) & =\frac{\alpha \beta}{\sigma \sqrt{2 \pi}} \exp \left\{-\left[\frac{\alpha^{2}}{2 \sigma}(1-\exp \{\right.\right. \\
& \left.\left.\left.\left.-\left(\operatorname{sgn} \Delta F_{D}\right)\left(\beta \Delta F_{D}\right)\right\}\right)^{2}+\left(\operatorname{sgn} \Delta F_{D}\right) \beta \Delta F_{D}\right]\right\} \\
& -\infty<\Delta F_{D}<\infty
\end{aligned}
$$

If we consider only the linear term of Eq. (5), then the probability density function of the drag force becomes from Eq. (7) as follows,

$$
f\left(\Delta F_{D}\right)=\frac{1}{\sqrt{2 \pi} a \sigma} \exp \left\{-\frac{\left(\Delta F_{D}\right)^{2}}{2 a^{2} \sigma^{2}}\right\}
$$

The probability density function $f\left(\Delta F_{D}\right)$ derived in Eqs. (10) and (11) are shown in figure 3. As can be seen in the figure, the probability density function given in Eq. (10) substantially deviates from normal distribution in that the probability density is greater for the larger forces than is the case for the normal distribution. 


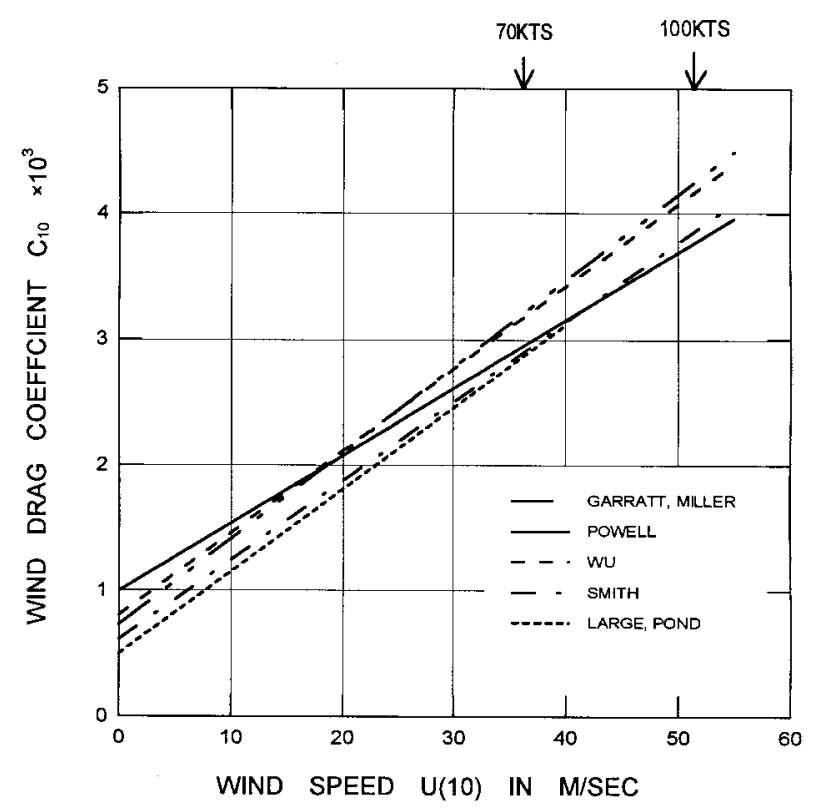

Fig. 4. Wind drag coefficient, $\mathrm{C}_{10}$, as a function of mean wind speed at 10 meter height.

\section{Energy Spectrum of Drag Force}

Since the wind-induced drag force is expressed as the sum of forces associated with linear and nonlinear (squared) terms of wind speed as shown in Eq. (5). Both terms are considered to be independent and the energy spectral density function of drag force may be expressed as

$$
S_{\Delta F_{D}}(\omega)=a^{2} S_{w}(\omega)+b^{2} S_{w|w|}(\omega)
$$

where $S_{w}(\omega)$ = turbulent wind spectrum

$S_{w|w|}(\omega)=$ spectrum for the squared wind velocity $w|w|$

$a, b=$ constants given in Eq. (6)

For the turbulent wind spectrum, $S_{w}(\omega)$, the following spectral formulation developed based on wind data obtained from measurements over a seaway is used for this study [7]:

$$
S\left(f_{*}\right)=\left\{\begin{array}{lll}
583 f_{*} & \text { for } \quad 0 \leq f_{*} \leq 0.003 \\
\frac{420 f_{*}^{0.70}}{\left(1+f_{*}^{0.35}\right)^{11.5}} & \text { for } & 0.003 \leq f_{*} \leq 0.1 \\
\frac{838 f_{*}}{\left(1+f_{*}^{0.35}\right)^{11.5}} & \text { for } \quad f_{*} \geq 0.1
\end{array}\right.
$$

where $f_{*}=$ dimensionless frequency $=\omega z / 2 \pi \bar{U}_{z}$

$S\left(f_{*}\right)=$ dimensionless spectrum $=\omega S(\omega) /\left(2 \pi u_{*}^{2}\right)$

$\bar{U}_{z}=$ mean wind speed at height $z$

$u^{*}=$ friction velocity

From Eq. (13), the dimensional turbulent wind

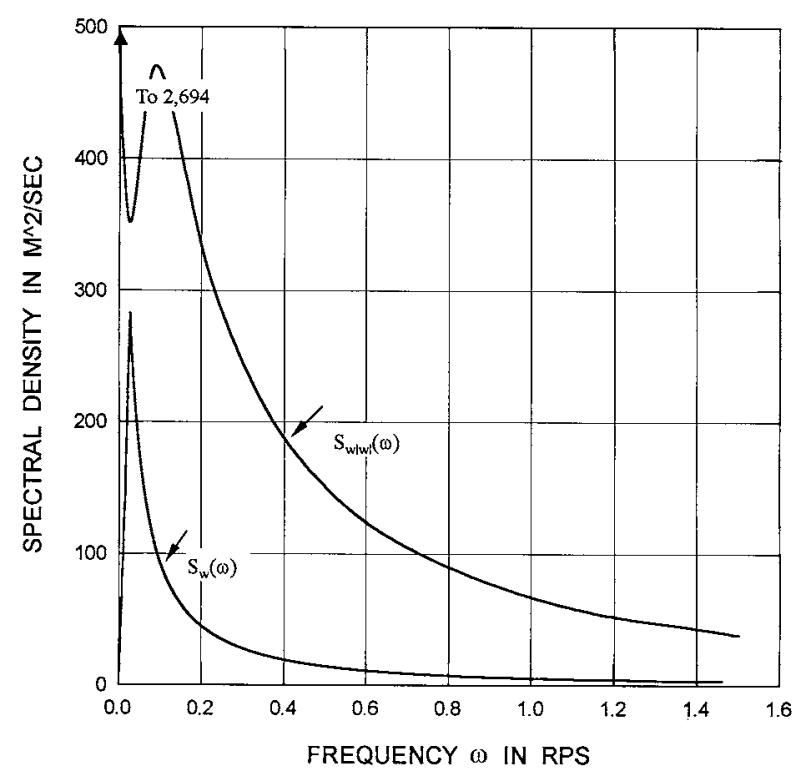

Fig. 5. Spectral density functions of turbulent wind $S_{w}(\omega)$ and $S_{w|w|}(\omega)$ for $\bar{U}_{30}=44.7 \mathrm{~m} / \mathrm{sec}, 87$ knots.

spectrum as a function of frequency $\omega$ can be written as,

$$
S(\omega)= \begin{cases}3314 u_{*}^{2} z \omega / \bar{U}_{z} & \text { for } 0 \leq \omega \leq 0.028 \\ \frac{116 u_{*}^{2}\left(z / \bar{U}_{z}\right)^{0.70}}{\omega^{0.30}\left[1+\left\{\omega z /\left(2 \pi \bar{U}_{z}\right)\right\}^{0.35}\right]^{11.5}} & \text { for } 0.028 \leq \omega \leq 0.936 \\ \frac{133 u_{* z}^{2}}{\bar{U}_{z}\left[1+\left\{\omega z /\left(2 \pi \bar{U}_{z}\right)\right\}^{0.35}\right]^{11.5}} & \text { for } 0.936 \leq \omega\end{cases}
$$

For evaluating the mean wind speed at height $z$ above the sea level, $\bar{U}_{z}$, and the friction velocity, $u_{*}$, the following formulae are used:

$$
\begin{aligned}
& \bar{U}_{z}=\bar{U}_{10}+2.5 u_{*} \ln (z / 10) \\
& u_{*}=\sqrt{C_{10}} \bar{U}_{10}
\end{aligned}
$$

where $\bar{U}_{10}=$ mean wind speed at $10 \mathrm{~m}$ height

$C_{10}=$ surface drag coefficient evaluated from wind measurements at $10 \mathrm{~m}$ height.

The surface drag coefficient, $C_{10}$, depends on mean wind speed, $\bar{U}_{10}$, as shown in Fig. 4. Among others[7], $\mathrm{Wu}$ 's results are based on data obtained for a wide range of wind velocities over a seaway; hence, his results shown in Figure 4 are used in the present study.

The turbulent wind spectrum, $S_{w}(\omega)$, for a mean wind speed of $44.7 \mathrm{~m} / \mathrm{sec}$ ( 87 knots) at a $30 \mathrm{~m}$ height above the sea level is shown in Figure 5. This mean wind speed is equivalent to $38.5 \mathrm{~m} / \mathrm{sec}$ ( $75 \mathrm{knots})$ at a 
$10 \mathrm{~m}$ level.

The spectral density function of the squared wind speed, $S_{w|w|}(\omega)$ can be evaluated by the following formula:

$$
S_{w|w|}=2\left\{R_{w}(0)\right\}^{2} \delta(\omega)+\frac{1}{\pi^{2}} S_{w}(\omega) * S_{w}(\omega)
$$

where $R_{w}(0)=$ auto-correlation function of wind speed with $t=0$, which is equal to the variance of the turbulent wind speed

$\delta(\omega)=$ delta function

The second term in Eq. (16) is the convolution integral of the turbulent wind spectrum and is evaluated numerica1ly.

The spectral density function of $S_{w|w|}(\omega)$ is also shown in Fig. 5. As can be seen, the spectral energy density $S_{w|w|}(\omega)$ is much greater than $S_{w}(\omega)$. Nevertheless, the contribution of the energy density of the squared wind speed, $S_{w|w|}(\omega)$, to the energy of the turbulent drag force is neg 1igible, since the value of $b^{2}$ in Eq. (12) is extremely small in comparison with $a^{2}$. Thus, it may safely be concluded that as far as the energy spectrum of turbulent drag force is concerned, the nonlinear term of the wind speed can be omitted.

\section{PROBABILITY DISTRIBUTION OF WIND- INDUCED DRAG FORCE}

\section{Joint Probability Distribution of Drag Force}

In order to obtain the probability distribution of the low frequency peaks (or maximum) of the windinduced drag force, it is necessary to obtain the joint probability distribution of drag force and its derivatives which in turn can be derived from the joint distribution of wind speed and its derivatives.

It is assumed that the turbulent wind speed, $w(t)$, is a Gaussian random process with zero mean; hence, the joint probability density function of $w(t)$ and its time derivatives, $\dot{w}(t)$ and $\ddot{w}(t)$, is given by the following trivariate norma1 distribution:

$$
f(w, \dot{w}, \ddot{w})=\frac{1}{(2 \pi)^{3 / 2} \sqrt{|\Sigma|}} \exp \left\{-\frac{1}{2} W \Sigma^{-1} W\right\}
$$

where $W^{\prime}=(w, \dot{w}, \ddot{w})$

$$
\Sigma=\text { covariance matrix of } W
$$

Since $w(t)$ is a Gaussian random process with zero mean, the covariance matrix, $\Sigma$, is given by

$$
\Sigma=\left(\begin{array}{ccc}
m_{0} & 0 & -m_{2} \\
0 & m_{2} & 0 \\
-m_{2} & 0 & m_{4}
\end{array}\right)
$$

where $m_{j}=j$-th moment of wind energy spectrum, $S_{w}(\omega)$

From Eqs.(17) and (18), the joint probability density function becomes

$$
\begin{aligned}
& f(w, \dot{w}, \ddot{w})=\frac{1}{(2 \pi)^{3 / 2}\left(m_{2} \Delta\right)^{1 / 2}} \\
& \times \exp \left\{-\frac{m_{4} w^{2}+\left(\Delta / m_{2}\right) \dot{w}^{2}+m_{0} \ddot{w}^{2}+2 m_{2} w \ddot{w}}{2 \Delta}\right\}
\end{aligned}
$$

where $\Delta=m_{0} m_{4}-m_{2}^{2}$

Next, the joint probability density function of the wind-induced drag force is derived by using the functional relationship between the turbulent wind speed and drag force as given in Eq. (9). For brevity, hereafter the drag force $\Delta F_{D}$ associated with turbulent winds and its derivatives are denoted by $D, \dot{D}$, and $\ddot{D}$. Then, by applying the technique for changing random variables, the joint probability density function of the drag force can be written as

$$
\begin{aligned}
& f(D, \dot{D}, \ddot{D})=[f(w, \dot{w}, \ddot{w})] \bullet|J| \\
& w=h_{1}(D, \dot{D}, \ddot{D}) \\
& w^{\prime}=h_{2}(D, \dot{D}, \ddot{D}) \\
& w^{\prime \prime}=h_{3}(D, \dot{D}, \ddot{D})
\end{aligned}
$$

where $|J|=\left|\begin{array}{lll}\frac{\partial h_{1}}{\partial D} & \frac{\partial h_{1}}{\partial \dot{D}} \frac{\partial h_{1}}{\partial \ddot{D}} \\ \frac{\partial h_{2}}{\partial D} & \frac{\partial h_{2}}{\partial \dot{D}} \frac{\partial h_{2}}{\partial \ddot{D}} \\ \frac{\partial h_{3}}{\partial D} & \frac{\partial h_{3}}{\partial \dot{D}} \frac{\partial h_{3}}{\partial \ddot{D}}\end{array}\right|=(\alpha \beta)^{3} \exp \{-3 \beta D\}$

and for $D \geq 0$

$$
\begin{aligned}
& h_{1}(D, \dot{D}, \ddot{D})=\alpha(1-\exp \{-\beta D\}] \\
& h_{2}(D, \dot{D}, \ddot{D})=\alpha \beta \dot{D} \exp \{-\beta D\} \\
& h_{3}(D, \dot{D}, \ddot{D})=\alpha \beta \ddot{D} \exp \{-\beta D\}-\alpha \beta^{2} \dot{D}^{2} \exp \{-\beta D\}
\end{aligned}
$$

Thus, the joint probability density function of the wind-induced drag force and its time derivatives becomes

$$
\begin{aligned}
& f(D, \dot{D}, \ddot{D})=\frac{(\alpha \beta)^{3}}{(2 \pi)^{3 / 2}\left(m_{2} \Delta\right)^{1 / 2}} \exp \{-3 \beta D\} \\
& \times \exp \left\{-\left[\begin{array}{l}
m_{4} \alpha^{2}\left(1-e^{-\beta D}\right)^{2}+\frac{\Delta}{m_{2}} \alpha^{2} \beta^{2} \dot{D}^{2} e^{-2 \beta D}+m_{0} \alpha^{2} \beta^{2}(\ddot{D} \\
\left.-\beta \dot{D}^{2}\right) e^{-2 \beta D}+2 m_{2} \alpha^{2} \beta\left(\ddot{D}-\beta \dot{D}^{2}\right) e^{-\beta D}\left(1-e^{-\beta D}\right)
\end{array}\right] / 2 \Delta\right\}
\end{aligned}
$$




\section{Probability Distribution of Peaks of Drag Force}

As stated in previous section, the analytical derivation of the probability density function of peaks (maximum) of the drag force induced by turbulent winds is the major area of concern of the present study. In particular, we are interested in turbulent winds, which have several local peaks during a half-cycle; thus being considered as a non-narrow-band random process. Hence, the probability density function of the peak of the drag force will be derived based on a non-narrowband random process. Following the concept originally developed by Rice (1945), the probability density function of the local positive peaks of drag force, denoted by $f(\xi)$, is given by

$$
f(\xi)=\frac{\int_{-\infty}^{0}|\ddot{D}| f(\xi, 0, \ddot{D}) d \ddot{D}}{\int_{0}^{\infty} \int_{-\infty}^{0}|\ddot{D}| f(D, 0, \ddot{D}) d \ddot{D} d D}
$$

It is noted that the formula given in Eq. (22) is applicable for the sample space $-\infty \leq D \leq \infty$. Since the analysis in this section is carried out for the sample space $0 \leq D \leq \infty, f(\xi)$ will be normalized later so that it satisfies the condition required for the probability density function.

The joint density function $f(D, 0, \ddot{D})$ can be written from Eq. (2l) as follows:

$$
\begin{aligned}
f(D, 0, \ddot{D}) & =\frac{\alpha^{3} \beta^{3} e^{-3 \beta D}}{(2 \pi)^{3 / 2}\left(m_{2} \Delta\right)_{1 / 2}} \times \exp \left\{-\left[m_{4} \alpha^{2}(1\right.\right. \\
& \left.-e^{-\beta D}\right)^{2}+m^{0} \alpha^{2} \beta^{2} \ddot{D}^{2} e^{-2 \beta D} \\
& \left.+2 m_{2} \alpha^{2} \beta \ddot{D}\left(1-e^{-\beta D}\right] /(2 \Delta)\right\}
\end{aligned}
$$

We first evaluate the numerator of Eq. (22), denoted by $M(\xi)$. From Eq. (23), $M(\xi)$ can be expressed in the following form:

$$
M(\xi)=K e^{-3 \beta \xi} \int_{-\infty}^{0}|\ddot{D}| e^{-\left\{P(\xi) \ddot{D}^{2}+2 Q(\xi) \ddot{D}^{2}+R(\xi)\right\}} d \ddot{D}
$$

where $K=(\alpha \beta)^{3} /\left\{(2 \pi)^{3 / 2}\left(m_{2} \Delta\right)^{1 / 2}\right.$

$$
\begin{aligned}
& P(\xi)=(\alpha \beta)^{2} m_{0} e^{-2 \beta \xi} /(2 \Delta) \\
& Q(\xi)=\alpha^{2} \beta m_{2} e^{-\beta \xi}\left(1-e^{-\beta \xi}\right) /(2 \Delta) \\
& R(\xi)=\alpha^{2} m_{4}\left(1-e^{-\beta \xi}\right)^{2} /(2 \Delta)
\end{aligned}
$$

By carrying out the integration with respect to $\ddot{D}$, Eq. (24) yields

$$
M(\xi)=\frac{\sqrt{2 \pi} \Delta K}{(\alpha \beta)^{2} m_{0}} \exp \{-\beta \xi\} \exp \left\{-\frac{\alpha^{2}}{2 m_{0}}\left(1-e^{-\beta \xi}\right)^{2}\right\}
$$

$$
\begin{aligned}
& \times\left[\frac{1}{2 \pi} \exp \left\{-\frac{\left(\alpha m_{2}\right)}{2 m_{0} \Delta}\left(1-e^{-\beta \xi}\right)^{2}\right\}\right. \\
& \left.+\frac{\alpha m_{2}}{\left(m_{2} \Delta\right)^{1 / 2}}\left(1-e^{-\beta \xi}\right) \Phi\left\{\frac{\alpha m_{2}}{\left(m_{2} \Delta\right)^{1 / 2}}\left(1-e^{-\beta \xi}\right)\right\}\right]
\end{aligned}
$$

where $K=(\alpha \beta)^{3} /(2 \pi)^{3 / 2}\left(m_{2} \Delta\right)^{1 / 2}$

$$
\begin{aligned}
& \Delta=\mathrm{m}_{0} \mathrm{~m}_{4}-\mathrm{m}_{2}^{2} \\
& \Phi(u)=\int_{-\infty}^{u}(1 / \sqrt{2 \pi}) \exp \left\{-u^{2} / 2\right\} d u
\end{aligned}
$$

Since the first term in the bracket of Eq. (25) is much smaller than the second term, we may simply write $M(\xi)$ as follows:

$$
\begin{aligned}
M(\xi) & =\frac{\sqrt{2 \pi} m_{2} K \Delta^{1 / 2}}{\alpha \beta^{2} m_{0}^{3 / 2}} \exp \left\{-\frac{\alpha^{2}}{2 m_{0}}\left(1-e^{-\beta \xi}\right)^{2}\right\} \\
& \times\left(e^{-\beta \xi}-e^{-2 \beta \xi}\right) \Phi\left\{-\frac{\alpha m_{2}}{\left(m_{0} \Delta\right)^{1 / 2}}\left(1-e^{-\beta \xi}\right)\right\}
\end{aligned}
$$

For evaluating the denominator of Eq. (22), denoted by $N$, integration with respect to $\ddot{D}$ is first carried out followed by the integration with respect to $D$. We may write $N$ in the following form:

$$
\begin{aligned}
N & =K \int_{-\infty}^{0} \int_{0}^{\infty}|\ddot{D}| e^{-3 \beta D} \\
& \cdot \exp \left\{-G\left(A e^{-2 \beta D}+2 B e^{-\beta D}+C\right)\right\} d D d \ddot{D}
\end{aligned}
$$

where $K=(\alpha \beta)^{3} /\left\{(2 \pi)^{3 / 2}\left(m_{2} \Delta\right)^{1 / 2}\right\}$

$$
\begin{aligned}
& G=\alpha^{2} / 2 \Delta \\
& A=m_{4}+m_{0} \beta^{2} \ddot{D}^{2}-2 m_{2} \beta \ddot{D} \\
& B=m_{2} \beta \ddot{D}-m_{4} \\
& C=m_{4} \\
& \Delta=m_{0} \cdot m_{4}-m_{2}^{2}
\end{aligned}
$$

After much lengthy mathematical manipulation, we have

$$
N=2 K \Delta^{2} /\left(C_{2} \alpha^{4} \beta^{3} m_{0} m_{4}\right)
$$

where $C_{2}=$ constant, 0.2

Thus, from Eqs. (26) and (27), can be derived as follows:

$$
\begin{aligned}
f(\xi) & =\frac{\sqrt{2 \pi} C_{2} \alpha^{3} \beta m_{2} m_{4}}{2 \sqrt{m_{0}} \Delta^{3 / 2}} \exp \left\{-\frac{\alpha^{2}}{2 m_{0}}\left(1-e^{-\beta \xi}\right)^{2}\right\} \\
& \times\left(e^{-\beta \xi}-e^{-2 \beta \xi}\right) \Phi\left\{\frac{\alpha m_{2}}{\left(m_{0} \Delta\right)^{1 / 2}}\left(1-e^{-\beta \xi}\right)\right\}
\end{aligned}
$$




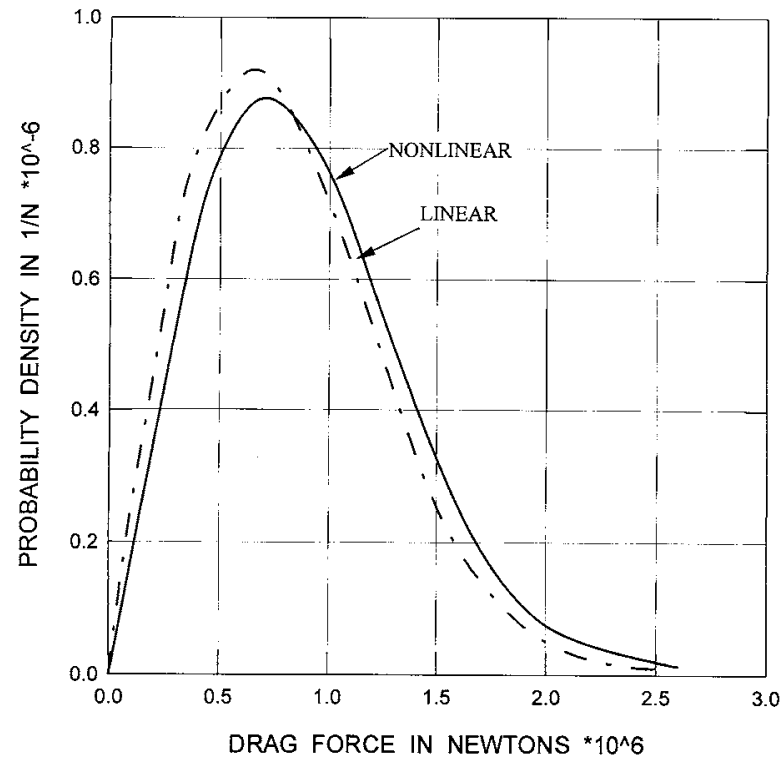

Fig. 6. Probability density functions of peak drag force evaluated through linear and nonlinear approaches.

Since $\beta \xi$ is small, on the order of less than 0.4 , the following approximation may be used:

$$
\begin{aligned}
& e^{-\beta \xi}-e^{-2 \beta \xi} \cong \beta \xi-\frac{3}{2}(\beta \xi)^{2} \\
& 1-e^{-\beta \xi} \cong \beta \xi
\end{aligned}
$$

Then, Eq. (29) becomes,

$$
\begin{aligned}
f(\xi) & =\frac{\sqrt{2 \pi} C_{2} \alpha^{3} \beta m_{2} m_{4}}{2 \sqrt{m_{0}} \Delta^{3 / 2}}\left(\beta \xi-\frac{3}{2}(\beta \xi)^{2}\right) \\
& \times \exp \left\{-\frac{\alpha^{2}}{2 m_{0}}(\beta \xi)^{2}\right\} \Phi\left\{\frac{\alpha m_{2}}{\left(m_{0} \Delta\right)^{1 / 2}} \beta \xi\right\}
\end{aligned}
$$

Next, as stated in connection with Eq. (22), $f(\xi)$ should be modified so that it satisfies the condition required for the probability density function. For this, by integrating from 0 to $\infty$, we have:

$$
\int_{0}^{\infty} f(\xi) d \xi=\frac{\sqrt{2 \pi} C_{2} \alpha^{3} m_{2} m_{4}}{2 \sqrt{m_{0}} \Delta^{3 / 2}} L
$$

where

$$
\begin{aligned}
L & =\frac{m_{0}}{2 \alpha^{2}}\left\{1+\frac{m_{2}}{\left(m_{0} m_{4}\right)^{1 / 2}}\right\}-\frac{9 \sqrt{2 \pi} m_{0}^{3 / 2}}{8 \alpha^{3}}-\frac{3 m_{2}\left(m_{0} \Delta\right)^{1 / 2}}{2 \sqrt{2 \pi} \alpha^{3} m_{4}} \\
& +\frac{3\left\{\pi-\tan ^{-1}\left(m_{2} / \Delta^{1 / 2}\right)\right\} m_{0}^{3 / 2}}{2 \sqrt{2 \pi} \alpha^{3}}
\end{aligned}
$$

By dividing Eq. (31) by Eq. (32), the probability density function applicable for the peaks of the drag force can be derived as follows:

$$
\begin{aligned}
f(\xi) & =\frac{1}{L} \beta\left\{\beta \xi-\frac{3}{2}(\beta \xi)^{2}\right\} \\
& \cdot \exp \left\{-\frac{\alpha^{2}}{2 m_{0}}(\beta \xi)^{2}\right\} \Phi\left\{\frac{\alpha m_{2}}{\left(m_{0} \Delta\right)^{1 / 2}} \beta \xi\right\}
\end{aligned}
$$

where $\mathrm{L}$ is defined in Eq. (33)

Fig. 6 shows the probability density function of the peaks of the turbulent wind-induced drag force computed by Eq. (34) on an offshore structure having a projected area $A=2 \times 10^{3} \mathrm{~m}^{2}$, The mean wind speed is $44.7 \mathrm{~m} / \mathrm{sec}$ ( 87 knots) at a 30 meter height above the water surface, and its spectrum is shown in Figure 5. Included also in the figure is the probability density function of the peaks evaluated by considering the drag force to be linear; (that is, by neglecting the 2 nd term of the turbulent wind speed given in Eq. 5). In this case, the probability density function is the Rayleigh probability distribution. In these computation, the moments $m_{2}$ and $m_{4}$ are computed by integration the spectrum up to the frequency $w=1.2 \mathrm{rps}$ in order to avoid an unrealistic increase in the value of the 4 th moment.

As can be seen in Figure 6, by taking the higher order turbulent wind speed into consideration, the probability density function of the peak drag force shifts toward larger values. In other words, the nonlinear approach yields higher probability density for large drag forces than the linear approach.

\section{ESTIMATION OF MAXIMUM WIND-INDUCED DRAG FORCE}

For the design of offshore structures, it is highly desirable to estimate the extreme wind-induced drag force, which the system will experience in a specified time period for a specified mean wind speed. For this, we first evaluate the number of peaks in a specified time period and then apply extreme value statistics. The number of peaks per unit time for a non-narrow-band random process is given by

$$
N=\frac{1}{4 \pi}\left(\sqrt{\frac{m_{2}}{m_{0}}}+\sqrt{\frac{m_{4}}{m_{2}}}\right)
$$

Then, the probable extreme drag force which is most likely to occur in T-hours, denoted by $\xi_{n}$, can be obtained as a solution of the following equation:

$$
\frac{1}{1-F\left(\xi_{n}\right)}=\frac{(60)^{2} T}{4 \pi}\left(\sqrt{\frac{m_{2}}{m_{0}}}+\sqrt{\frac{m_{4}}{m_{2}}}\right)=(60)^{2} T N
$$


where $F()=$ cumulative distribution function of the peaks of drag force

Equation (35) implies that the probability that the probability that the peak drag force $\xi_{n}$ exceeds the probable extreme value is once in $(60)^{2} \mathrm{TN}$ peaks.

It is known, however, that the probability that the extreme value will exceed the probable extreme value is theoretically $1-e^{-1}=0.632$. Since this value is very high, the probable extreme value cannot be considered as a design value. For design consideration we may choose an extreme value for which the probability of being exceeding is a preassigned very small value $\alpha$, called the risk [8]. The design extreme value, denoted by $\xi_{n}$, can then be evaluated as a solution of the following equation:

$$
\frac{1}{1-F\left(\xi_{n}\right)}=\frac{(60)^{2} T N}{\alpha}
$$

Figure 7 shows a comparison of extreme values evaluated through both the linear and nonlinear approach. The nonlinear approach yields an 8.0 percent increase in the probable extreme drag force, and a 6.0 percent increase in the design extreme drag force for the present example.

\section{CONCLUSIONS}

This paper presents the results of a study to statistically estimate low frequency turbulent wind drag force (including extreme values) acting on a floating offshore structure. In evaluating the drag force, forces associated with turbulent wind speeds are considered using both the linear and nonlinear (squared term) approach. From the results of the analysis, the following conclusions are drawn:

The probability density function of the turbulent drag force including the nonlinear term substantially deviates from a normal distribution in that the probability density is greater for the larger forces than is the case for the normal distribution.

The probability density function of the peak drag force shifts toward larger values by taking the higher order turbulent wind speed into consideration. In other words, the nonlinear approach yields higher probability density for large drag forces than the linear approach.

In evaluating the variance of the turbulent windinduced drag force from a wind spectrum, it is necessary to consider the spectrum of the squared wind speed. The spectral density function of the squared wind speed, $S_{w|w|}(\omega)$, is very large in comparison with the spectrum of wind speed, $S_{w}(\omega)$, however, the contribution of the former to the variance of the drag force is extremely small.

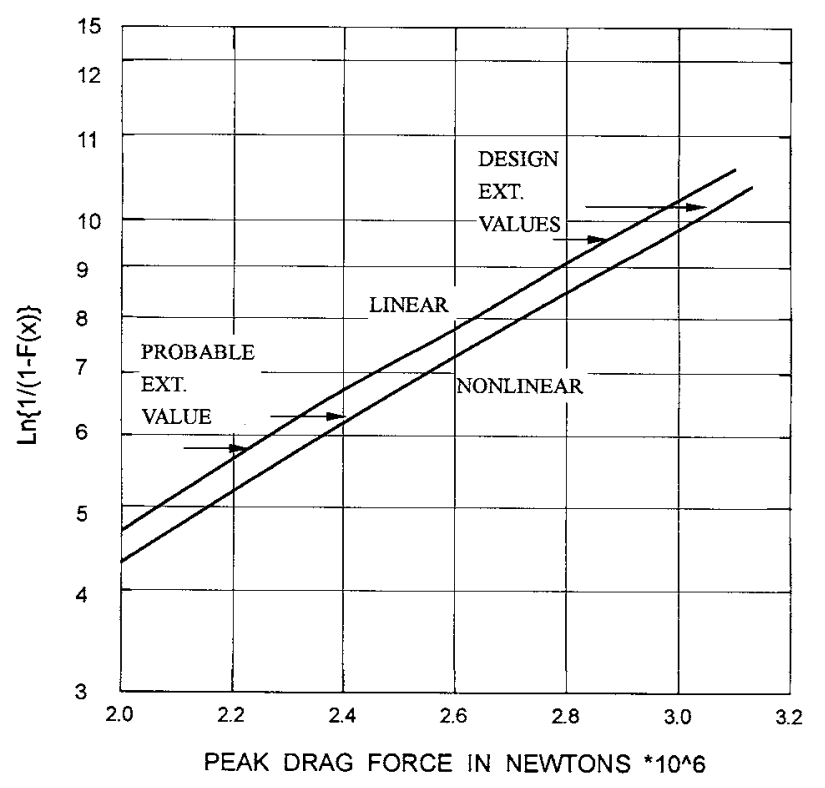

Fig. 7. Probable extreme and design extreme values of peak drag force evaluated through linear and nonlinear approaches.

Extreme wind-induced drag forces are evaluated through both the linear and nonlinear approach on an offshore structure having a projected area of $2,000 \mathrm{~m}^{2}$ for a wind speed of $44.7 \mathrm{~m} / \mathrm{sec}$ ( $87 \mathrm{knots}$ ) at a $30 \mathrm{~m}$ height. The wind spectral formulation developed broad on wind data obtained from measurements over a seaway is used in the computations. The results of the computations show that the nonlinear approach yields an 8.0 percent increase in the probable extreme drag force, and a 6.0 percent increase in the design extreme drag force.

\section{ACKNOWLEDGEMENT}

The authors would like to thank the National Science Council of Taiwan for funding this research (Project No. NSC 87-2611-019-030)

\section{REFERENCE}

1. Aguirre, J.E., Boyce, T. R., "Estimation of Wind Forces on Offshore Drilling Platforms," Transaction, Royal Institution of Naval Architects, 1974, Vol. 116, pp. 93109.

2. Jang, J.J., "Analysis of Wind Induced Dynamic Response of Offshore Structures," Proceedings of the 20th Ocean Engineering Conference in Taiwan, 1998, pp. 189-196.

3. Kaimal, J.C., et al., "Spectral Characteristics of Surface Layer Turbulence," Journal of the Royal Meteorological Society, 1972, Vol. 98, pp. 563-589.

4. Kareem, A., "Dynamic Effects of Wind on Offshore 
Structures," Proc. 12th Offshore Techn. Conf., OTC 3764, 1980, Vol. 2, pp. 235-246.

5. Kareem, A., "Wind-Exciting Response of Building in Higher Mode," Journal of the Structural Division, ASCE. 1981, Vol. 107, No. ST4, pp. 701-706.

6. Newland, D.E., An Introduction to Random Vibrations and Spectral Analysis, 2nd Edition, Longman, New York.

7. Norton, D.J., "Mobile Offshore Platform Wind Loads," Proc. 13th Offshore Techn., OTC 4123, 1981, Vol. 4, pp 77-88.

8. Ochi, M.K., Shin, Y.S., "Wind Turbulent Spectra for Design Consideration of Offshore Structures," Proc. 20th Offshore Techn. Conf., OTC 5736, 1988, pp. 461467.

9. Ochi, M.K., “On Prediction of Extreme Values,” Journal Ship Res., 1973, Vol. 17, pp. 29-37.

10. Simiu, E., "Wind Spectra and Dynamic Along-Wind Response," Journal of the Structural Division, ASCE, 1974, Vol. 100, No. 9, pp. 1897-1910.

11. Shiraishi, N., "Aerodynamic Response of Bridge to Natural Winds," Wind Effect on Structures, Univ. of Tokyo.

12. Simiu, E., Shaver, J.R., "Wind Loading and Reliabilitybased Design," Wind Engineering, Proc. 5th Int. Conf., 1979, Vol. 2, pp1281-1292.

13. Vickery, B.J., Freathy, P.E., "Wind Loads on Semisubmersible Offshore Platforms," Proc. 18th Offshore Techn. Conf., OTC 5174, 1986, Vol. 2, pp. 199 204.

14. Vickery, B.J., Pike, P.J., "An Investigation of Dynamic Wind Loads on Offshore Platforms," Proc. 17th Offshore Techn. Conf., OTC 4955, 1985, Vol. 2, pp. $527-$ 541.

\section{離岸結構物最大設計風力之分析}

$$
\text { 張 景 鐘 郭志信 }
$$

國立台灣海洋大學河海工程學系

$$
\text { 摘 要 }
$$

本文主要是利用風速能量頻譜方程式和機率可 靠度分析方法, 來分析計算作用在離岸結構物上的最 大可能風拖电力。在有關風拖曳力計算方面, 本研究 考慮紊流風速線性及非線性 (平方項) 兩部份, 利用 近年來有關風速能量頻譜的研究成果來估算風速能量 頻譜密度的數學公式, 並加以應用於本研究中。對於 計算由風引起的最大紊流拖电力之機率密度函數, 本 文將其視爲一非窄帶隨機過程處理, 以簡化的單一項 式表示關於風速與紊流風拖曳力的關係方程式和機率 密度函數。最後, 藉由極值機率統計的方法可以求得 離岸結構物風力可能的最大值和設計的最大值, 其結 果將有助於未來離岸結構物風力設計之參考。

關鍵字: 風力、離岸結構物、結構設計、機率密度函 數。 